\title{
Cost-Effectiveness Analysis of the Treatment Strategies with or without Opioid Medications in Surgery-Eligible Patients with Osteoarthritis in Japan
}

\author{
Tomoyuki Takura $^{1} \cdot$ Akira Yuasa $^{2} \mathbb{D} \cdot$ Naohiro Yonemoto $^{2} \cdot$ Sven Demiya $^{3} \cdot$ Hiroyuki Matsuda $^{3} \cdot$ Nozomi Ebata $^{4}$. \\ Koichi Fujiii ${ }^{4}$ Muneaki Ishijima ${ }^{5}$
}

Accepted: 19 July 2021 / Published online: 10 August 2021

(c) The Author(s) 2021

\begin{abstract}
Aim The aim of this study was to evaluate the cost effectiveness of treatment strategies without opioid medications (nonopioid treatment strategy) versus strategies with opioid medications (opioid treatment strategy) among surgery-eligible patients with osteoarthritis (OA) of the knee or hip in Japan.

Materials and Methods We built a Markov cohort model to evaluate outcomes for the treatment strategies in surgery-eligible patients aged $\geq 65$ years with OA of the knee or hip in Japan. The opioid treatment strategy as an intervention includes a health state with opioid medication in the treatment pathway. On the other hand, for the non-opioid treatment strategy, there is no health state with opioid medication. A targeted literature review and database analysis were conducted to identify and define the values of the variables included in the model. The time horizon was set to 30 years, and a $2 \%$ discount was applied for cost and quality-adjusted life-years (QALYs). Sensitivity analysis and scenario analysis were performed in the model. The outcomes were QALYs and the incremental cost-effectiveness ratio (ICER).

Results In the base-case analysis, the non-opioid treatment strategy was dominant over the opioid treatment strategy and associated with an incremental cost and QALYs of - 53,878 JPY (- 499 USD) and 0.03 QALYs, respectively, in patients with knee OA, and - 54,129 JPY (- 502 USD) and 0.02 QALYs, respectively, in patients with hip OA. One-way sensitivity analysis showed the ICER was most sensitive to the QALY for opioid monotherapy. Probabilistic sensitivity analyses showed a high degree of uncertainty associated with the results.

Limitations Study limitations included assumptions related to transition probabilities of the health states, and a lack of Japanese-specific data for transition probabilities, incidence of adverse events and utility values.

Conclusions This study suggests that the non-opioid treatment strategy is cost effective compared with the opioid treatment strategy in the management of surgery-eligible patients with OA of the knee or hip. However, this final conclusion may not be accurate as the methodology is heavily reliant on assumptions.
\end{abstract}

Akira Yuasa

akira.yuasa@pfizer.com

1 Department of Healthcare Economics and Health Policy, Graduate School of Medicine, The University of Tokyo, Tokyo, Japan

2 Health and Value, Pfizer Japan Inc., Shinjuku Bunka Quint Building, 3-22-7, Yoyogi, Shibuya-ku, Tokyo 151-8589, Japan

3 IQVIA Solutions Japan K.K., Tokyo, Japan

4 Medical Affairs, Pfizer Japan Inc, Tokyo, Japan

5 Department of Medicine for Orthopaedics and Motor Organ, Juntendo University Graduate School of Medicine, Tokyo, Japan

\section{Key Points for Decision Makers}

This study suggests that the non-opioid treatment strategy is cost effective compared with the opioid treatment strategy in patients with osteoarthritis of the knee or hip, although the results are associated with considerable uncertainty.

In the case of higher utility with opioid treatments, the treatment strategy for opioids was cost effective and the incremental cost-effectiveness ratios remained within the cost-effectiveness threshold. 


\section{Background and Introduction}

Osteoarthritis (OA) is a chronic degenerative and progressive joint disease that affects more than 250 million people worldwide [1] and is associated with decreased quality of life (QoL), loss of productivity and increased healthcare costs [2-4]. OA most frequently occurs in the spine, hips, knees or hands, but can affect any joint [5, 6].

OA of the knee and hip is characterized by chronic musculoskeletal pain and reduced mobility, causing difficulty in walking and climbing stairs [7]. Elderly populations are particularly affected in terms of severity and prevalence. Within Japan, the prevalence of OA of the knee or hip in patients aged $\geq 50$ years is estimated to be $55.6 \%$ and $2.4 \%$, respectively $[8,9]$. An epidemiological study reported that the mean age ( \pm standard deviation) of OA patients is $68.8 \pm 13.1$ years in Japan [10].

An OA curative treatment is still absent, therefore current clinical practice is to manage symptoms through alleviation of pain, stiffness reduction and maintenance of the functional capacities of the affected joints, as well as to improve QoL [4]. This is in line with the Japanese national guidelines on OA from the Osteoarthritis Research Society International (OARSI) and guidelines from the American College of Rheumatology [11, 12]. Both guidelines strongly recommend rehabilitation and surgery as nonpharmacological treatments, and nonsteroidal anti-inflammatory drugs (NSAIDs), acetaminophen (paracetamol) and intra-articular injection of steroid and hyaluronate as pharmacological treatments for OA of the knee and hip. Weak opioids are recommended for patients with refractory pain when other pharmacological agents have proved ineffective or are contraindicated. However, prescription of opioids tends to be low and only weak opioids (codeine, tramadol and buprenorphine) are recommended [10,13, 14].

Due to the steadily growing aged population and the high incidence of $\mathrm{OA}$ in this population, the cost of treating $\mathrm{OA}$ is having an increasingly significant impact on healthcare budgets [15-17]. Therefore, treatments should be efficacious and cost effective.

Several cost-effectiveness studies have recently been undertaken in the USA to elucidate the value of the treatments indicated for OA. They found that opioid treatments are less effective and more expensive than non-opioid treatments [18, 19]. However, there are few health economic analysis studies on OA of the hip in Japan, and few studies assessing the cost effectiveness of treatments for OA. Considering the differences in clinical practices and healthcare settings between the USA and Japan, there is a need to explore the health economic outcomes for patients with OA in Japan.

This study was conducted to evaluate the cost effectiveness of a non-opioid treatment strategy excluding opioid medications versus an opioid treatment strategy including opioid medications, in surgery-eligible patients with OA of the knee or hip in Japan.

\section{Methods}

The target population was set to patients diagnosed with OA of the knee or hip, and who were aged 65 years or older (as this population is most susceptible to the major causes of disability in OA [10, 20]), who were eligible for total knee arthroplasty (TKA) or total hip arthroplasty (THA). The treatment pathway according to the OA guidelines for the target population starts with the prescription of non-opioid medications. Opioid medications are considered for patients who are refractory to other medications and who experience strong pain. Surgery is performed after pharmacological treatment.

A targeted literature review was conducted in MEDLINE and Igaku Chuo Zasshi from December 2014 to December 2019 to obtain evidence of knee and hip osteoarthritis.

\subsection{Model Structure}

The model assessed the cost effectiveness of the treatment strategies with opioid medications (opioid treatment strategy) as the intervention versus the treatment strategies without opioid medications (non-opioid treatment strategy) as the comparator in patients with OA of the knee or hip, and reflected the clinical guidelines, clinical settings and treatment patterns in Japan [11,21]. The treatment strategies were selected based on the Japanese guidelines for OA in addition to previously published literature $[10,11]$. The model represents the strategy in which no opioids are considered in clinical practice versus the strategy in which opioids are considered, meaning there is another option (i.e., opioid medications) in the opioid treatment strategy. This model was built to investigate cost effectiveness for the patients who were eligible for TKA or THA in each strategy with or without opioid medications.

A Markov cohort model was built for the cost-effectiveness analysis (CEA) (Fig. 1). Existing OA models described in the literature by Katz et al. and Smith et al. were used as a basis for the model structure and expanded to enable comparison of the selected treatment strategies [18, 19]. Additionally, the treatment strategies were confirmed by a clinical expert. The initial state of both treatment strategies was the non-opioid therapy state. The patients in the non-opioid treatment strategy can transit to the non-opioid therapy state followed by the surgery and post-surgery states. On the other hand, patients in the opioid treatment strategy can transit to either the opioid therapy or surgery states after the non-opioid therapy state. The patients undergoing surgery transit to the post-surgery 
state. In the opioid therapy state, opioid (opioid monotherapy) or opioid with non-opioid medications (combination therapy) are prescribed. In both strategies, it is possible to undergo revision surgery due to complications and hence patients transit from the post-surgery to the surgery state.

The non-opioid therapies included the following medications: NSAIDs (oral and transdermal), acetaminophen, hyaluronate injection, steroid injection and duloxetine. The opioid therapies included weak opioids (tramadol, codeine and buprenorphine) and a combination of tramadol with acetaminophen. These medications, which were recommended in the clinical guidelines and/or widely prescribed, were considered for included treatments in the model. However, strong opioids were not included because there is no particular recommendation for them in the clinical guidelines and the prescription rate for strong opioids is quite low in Japan $[10,11,21]$.
The cycle length was set to 3 months and validated by experts. The health states of surgery and post-surgery were included to better understand the treatments during the perioperative period as part of the therapy.

The outcomes of this analysis were quality-adjusted lifeyears (QALYs) and the incremental cost-effectiveness ratio (ICER), defined as the ratio of incremental costs (in Japanese yen, JPY) to incremental QALYs, in accordance with the Japanese guidelines for health economic evaluation [22]. We evaluated the ICER for comparison with a willingnessto-pay (WTP) threshold of 5 million JPY (46,335 USD) per QALY [23].

The model was built and run using the TreeAge Healthcare decision analysis software, version 2020 (TreeAge Software, LLC, Williamstown, MA, USA).

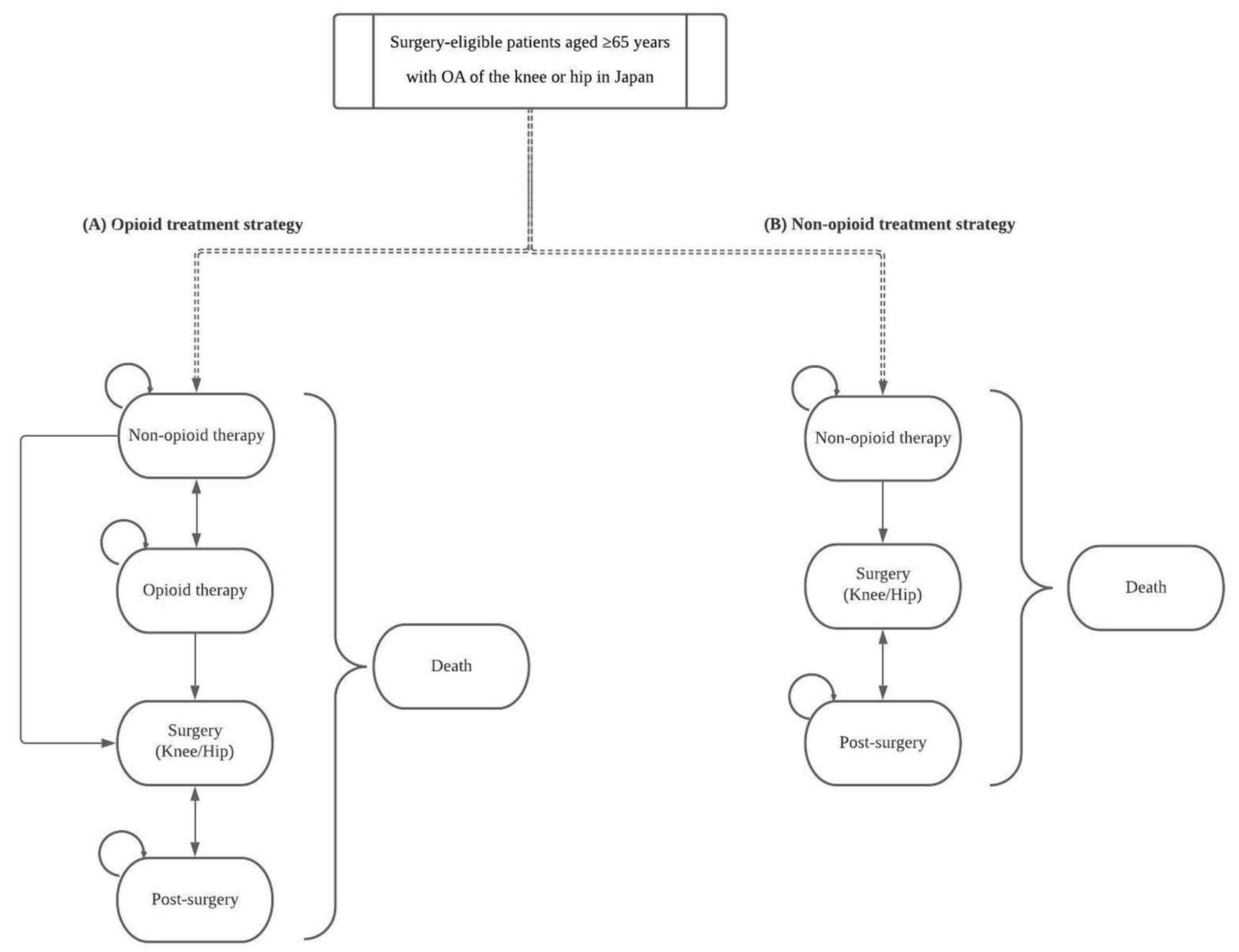

Fig. 1 Model structure. A Opioid treatment strategy; B non-opioid treatment strategy. $O A$ osteoarthritis 


\subsection{Study Population, Perspective and Discounting}

The patients in the study population were initially treated with non-invasive non-opioid medications. The perspective adopted was that of the healthcare payer. The time horizon was set to 30 years (lifetime) to consider a sufficiently long time horizon; as the mean life expectancy for Japan is 84 years [24]. A 2\% discount was applied for cost and effectiveness and aligned with the health technology guidelines of Japan [22]. Model properties and assumptions used in the analysis were reported according to the Consolidated Health Economic Evaluation Reporting Standards (CHEERS) checklist [25].

\subsection{Model Inputs}

Parameter values were obtained from two sources: literature and a hospital-based administrative claims database created by Medical Data Vision Co. Ltd (MDV; Tokyo, Japan) [26]. For the MDV database analysis, definitions of the target population and medications were primarily derived from Akazawa et al. [10]. Detailed definitions are reported in Appendix 1 (see electronic supplementary material [ESM]). The costs of medications, procedures and adverse events (AEs) were procured from the MDV database.

\subsubsection{Transition Probabilities}

A study by Zhang et al. described a multistate transition model for knee OA pain change that was used as a proxy for the transition probabilities required in the model [27].

Transition probabilities were based on the number of transitions between pain states (none/mild, moderate and severe pain) as defined by the Western Ontario and McMaster Universities Osteoarthritis Index (WOMAC) scores over a period of 12 weeks (3 months) [27]. For the model, it was assumed that the transitions between the three pain states (none/mild, moderate and severe pain) in the literature reflect the transitions between the non-opioid, opioid and surgery health states in the model, respectively (Appendix 2, see ESM). This resulted in the following simple assumptions for the non-opioid and opioid treatment strategies:

- Non-opioid treatment strategy: the non-opioid therapy state corresponds to none/mild and moderate pain; and the surgery state corresponds to severe pain.

- Opioid treatment strategy: the non-opioid therapy state corresponds to none/mild pain; the opioid therapy state corresponds to moderate pain; and the surgery state corresponds to severe pain. Note that in the opioid treatment strategy, mono-opioid and combination medications (with non-opioids and opioids) were both considered in the opioid health state (Appendix 3).
- All patients in the surgery state transition to the postsurgery state (except for those who died).

The transition probabilities from post-surgery to surgery for revision surgery due to complications were obtained from Piscitelli et al. [28] and were adjusted to account for all-cause mortality, which was based on Japanese life tables from the Ministry of Health, Labour and Welfare of Japan [29]. The transition probabilities for the non-opioid treatment strategy were derived from those of the opioid treatment strategy. The base-case transition probabilities of the non-opioid and opioid treatment strategies are presented in Table 1. The same transition probabilities were used for hip $\mathrm{OA}$ as no other evidence could be obtained. The transition to surgery for both treatment strategies is similar if we consider the fact that an additional health state was included in the opioid treatment strategy. The probability that patients transition to surgery in the opioid treatment strategy for opioids is $17.37 \%$ and for non-opioids is $2.41 \%$. The values were obtained from Zhang et al. [27], as previously discussed, and necessary assumptions were made to run the analysis. In the non-opioid treatment strategy, which only considers non-opioid treatments, this probability was adjusted as there is only one way to proceed to surgery. The probability of no opioids to surgery is $9.89 \%$ and was estimated by summing the probability of having surgery for the opioid treatment strategy and dividing by 2 , as patients can only go via one health state to surgery. From the MDV data, the proportions consisted of $14.71 \%$ for mono-opioid medications and $85.29 \%$ for combination medications.

\subsubsection{Adverse Events (AEs)}

AEs for non-opioid and opioid treatments were derived from the literature [18]. In Japan, NSAIDs are the most prescribed non-opioid treatment [10]. It was assumed that the AEs of ibuprofen were equal to those of loxoprofen and used for the model according to the references, which indicate that loxoprofen is a good representative for NSAIDs in Japan [30, 31]. The AE rates reported by Katz et al. for celecoxib and ibuprofen were assumed to be representative of AEs for NSAIDs and were applied to all treatments that were included in the non-opioid health state [18]. These included major cardiovascular events (myocardial infarction, stroke and heart failure) and major gastrointestinal events.

For the opioid treatments, three opioids (tramadol, buprenorphine and codeine) were considered for inclusion. Because tramadol was the most prescribed opioid treatment for patients with OA based on the MDV analysis (Appendix 3, see ESM), it was decided that tramadol is representative for the use of weak opioids for patients with OA in Japan. The AE rates of tramadol are used for 
Table 1 Base-case transition probabilities used in the opioid and non-opioid treatment strategies

\begin{tabular}{lrl}
\hline Probabilities & Base case (\%) & Source for base case \\
\hline Opioid treatment strategy & 56.030 & {$[27]$} \\
Probability of remaining non-opioid & 6.230 & {$[27]$} \\
Probability of non-opioids to opioids (monotherapy) & 35.320 & {$[27]$} \\
Probability of non-opioids to opioids (combination therapy) & 2.410 & {$[27]$} \\
Probability of non-opioid to surgery & 25.980 & {$[27]$} \\
Probability of opioids to non-opioids & 8.500 & {$[27]$} \\
Probability of (any) opioids to opioids (monotherapy) & 48.150 & {$[27]$} \\
Probability of (any) opioids to opioids (combination therapy) & 17.370 & {$[27]$} \\
Probability of opioids to surgery & 100.000 & Assumption \\
Probability of surgery to post-surgery & 0.001 & {$[28]$} \\
Probability of post-surgery to surgery (reoperation), knee & 0.004 & {$[28]$} \\
Probability of post-surgery to surgery (reoperation), hip & & \\
Non-opioid treatment strategy & 90.110 & {$[27]$} \\
Probability of remaining non-opioid & 9.890 & {$[27]$} \\
Probability of non-opioid to surgery & 100.000 & Assumption \\
Probability of surgery to post-surgery & 0.001 & {$[28]$} \\
Probability of post-surgery to surgery (reoperation), knee & 0.004 & {$[28]$} \\
Probability of post-surgery to surgery (reoperation), hip &
\end{tabular}

opioid medications. AEs considered in the model included fractures, nausea, vomiting and constipation, and were based on the AEs reported by Katz et al. for tramadol [18]. Again, it was assumed that the same AE rates applied for all the opioid treatments included. The costs associated with somnolence are not recorded in clinical settings in Japan and were therefore excluded from the analysis [32]. In addition, the efficacy and cost due to AEs for surgery and complications in the post-surgical state were not considered in the model. This is because the efficacy and cost of AEs relating to surgery are an expected trade-off between both treatment strategies.

No disutility due to AEs was applied in the model as this is already accounted for by the utility value of the health state [33]. Furthermore, discontinuation due to AEs was not considered in the model. Table 2 shows the probabilities of AEs for the two treatment strategies plus causes of death.

\subsubsection{Cost}

Costs included in the CEA were derived from the literature and MDV database analysis [34]. Three main categories of costs were included: medication costs, procedure costs and the cost of AEs (Table 3).

The costs of medication and procedures were generated by MDV based on the prescribed daily dose according to the standard of care for patients with OA in Japan. Medications included were those most commonly prescribed in Japan and were selected according to the number of prescriptions in each category; for example, NSAIDs (oral, transdermal) and acetaminophen for non-opioid treatment, and tramadol for opioid treatment.

For AEs costs, the costs of fractures was obtained from Taguchi et al. [35]. The treatments required in response to major cardiovascular and gastrointestinal AEs and opioidrelated minor toxicities (nausea/vomiting, constipation) were identified in the literature [32, 36-42], and the corresponding costs were obtained from MDV. All costs were inflated to 2020 prices [43].

Results in Japanese yen were converted to US dollars according to the average rate published in 2019 by the Bank of Japan, and the rate was adjusted by Purchasing Power Parities published by the OECD in 2019 (1 USD $=107.91$ JPY) [44, 45].

\subsubsection{Utilities}

No relevant utility data was identified in the targeted literature review for a Japanese population with OA, although a patient-reported outcome study using the EQ-5D-5L questionnaire was identified that reported the utility values of the included health states for a Spanish population [33]. These values accounted for the baseline utility of the disease (OA of the knee or hip), the treatment (non-opioid, opioid, surgery and post-surgery), and the disutility due to the treatment (AEs) (Table 4).

For the opioid treatment, two categories of utility values were identified as potentially relevant: opiate derivatives ( 0.538 and 0.498 for knee and hip, respectively) and opioid pain medication ( 0.333 and 0.435 for knee and hip, respectively). However, because of the small number of patients 
Table 2 Probabilities of AEs for the opioid and non-opioid strategies, and all-causes of death

\begin{tabular}{|c|c|c|c|c|}
\hline \multirow[t]{2}{*}{ AEs } & \multicolumn{4}{|c|}{ Three-month probabilities (literature, $\%$ ) } \\
\hline & First year & $\begin{array}{l}\text { Subsequent } \\
\text { year }\end{array}$ & $\begin{array}{l}\text { Type of } \\
\text { distribu- }\end{array}$ & References \\
\hline
\end{tabular}

\begin{tabular}{|c|c|c|c|c|}
\hline \multicolumn{5}{|c|}{ Opioid treatment strategy } \\
\hline \multicolumn{5}{|l|}{ Non-opioid } \\
\hline $\begin{array}{c}\text { Major CV } \\
\text { events }\end{array}$ & 0.19 & 0.09 & Beta & [18] \\
\hline $\begin{array}{c}\text { Major GI } \\
\text { events }\end{array}$ & 0.20 & 0.10 & Beta & [18] \\
\hline \multicolumn{5}{|l|}{ Opioid } \\
\hline Fractures & 1.33 & 0.67 & Beta & [18] \\
\hline \multicolumn{5}{|c|}{ Minor toxicities, opioid } \\
\hline $\begin{array}{l}\text { Nausea/vom- } \\
\text { iting }\end{array}$ & 2.95 & 2.95 & Beta & [18] \\
\hline Constipation & 5.05 & 5.05 & Beta & [18] \\
\hline Somnolence & 22.98 & 22.98 & Beta & [18] \\
\hline \multicolumn{5}{|c|}{ Non-opioid treatment strategy } \\
\hline \multicolumn{5}{|l|}{ Non-opioid } \\
\hline $\begin{array}{c}\text { Major CV } \\
\text { events }\end{array}$ & 0.19 & 0.09 & Beta & [18] \\
\hline $\begin{array}{c}\text { Major GI } \\
\text { events }\end{array}$ & 0.20 & 0.10 & Beta & [18] \\
\hline \multicolumn{5}{|c|}{ Mortality for both strategies } \\
\hline $\begin{array}{l}\text { Major CV } \\
\text { events }\end{array}$ & 6.89 & 6.89 & Beta & [18] \\
\hline $\begin{array}{c}\text { Major GI } \\
\text { events }\end{array}$ & 2.81 & 2.81 & Beta & [18] \\
\hline Fractures & 2.12 & 2.12 & Beta & [18] \\
\hline
\end{tabular}

Literature-based AE estimates were based on ibuprofen and celecoxib for the non-opioid treatment strategy, and tramadol for the opioid treatment strategy. Clinical expert-based AE estimates were based on loxoprofen for the non-opioid treatment strategy, and tramadol and a combination of tramadol and acetaminophen for the opioid treatment strategy

$A E s$ adverse events, $C V$ cardiovascular, $G I$ gastrointestinal

in the opioid pain medication group, the utility values of the opiate derivatives were used in the model for the opioid health state [33]. For knee and hip surgery, the utility was assumed to be the average of that associated with waiting for the prosthetic implant and rehabilitation/physiotherapy because there is no exact utility value. Given the example, the utility value of knee surgery was derived from the average of that associated with waiting for the prosthetic implant and rehabilitation/physiotherapy $(0.120=[0.100+0.139] / 2$, Table 4$)$. The utility value of post-surgery was assumed to be equivalent to the utility value corresponding to prosthetic implant in the previous 6 months [33].

\subsection{Sensitivity Analysis}

One-way sensitivity analysis were performed using some parameters such as AEs due to non-opioid therapy ranging within the 95\% confidence interval (and when not available, ranging within $\pm 20 \%$ ) and probabilistic sensitivity analysis running a total of 5000 simulations. The one-way sensitivity analysis results are presented as tornado diagrams and the probabilistic sensitivity analysis results are presented as both cost-effectiveness scatter plots and cost-effectiveness acceptability curves (CEACs), in all cases comparing the opioid versus the non-opioid treatment strategies.

\subsection{Scenario Analysis}

A scenario using lower utility was included in this analysis. We used the lower utility of opioid medications $(0.333$ and 0.435 for knee and hip, respectively) for the surgery-eligible patients with OA rather than the alternative utility of opiate derivatives for the base-case setting (Table 4) [33].

\section{Results}

\subsection{Base-Case Analysis}

The results of the base-case analysis for OA of the knee and hip are shown in Table 5. In patients with knee OA, the use of opioids was associated with an incremental cost of 53,878 JPY (499 USD) and an incremental effectiveness of - 0.03 QALYs, making the non-opioid treatment strategy dominant over the opioid treatment strategy. Similarly, the use of opioids in patients with OA of the hip was associated with an incremental cost of 54,129 JPY (502 USD) and an incremental effectiveness of -0.02 QALYs, indicating the non-opioid treatment strategy is dominant over the opioid treatment strategy.

\subsection{Sensitivity Analysis}

Figure 2 shows the eleven results of the one-way sensitivity analysis from most to least important, in which the utility for opioids (opioid monotherapy) had the greatest impact on the ICER in the model. The utility for postsurgery was listed as the second most important parameter to impact the model, and time horizon (10-30 years) was the third.

Probabilistic sensitivity analyses showed that there was considerable uncertainty about the results of the base-case analysis (Fig. 3). From the CEAC curve in Fig. 4, 51.34\% 
Table 3 Key cost inputs (osteoarthritis of the knee or hip)

\begin{tabular}{lll}
\hline Cost category & $\begin{array}{l}\text { Cost per 3 } \\
\text { months (JPY) }\end{array}$ & Type of distribution \\
\hline
\end{tabular}

\begin{tabular}{|c|c|c|}
\hline \multicolumn{3}{|c|}{ Non-opioid treatment strategy (NSAIDs, acetaminophen, steroids, hyaluronate injection) } \\
\hline Treatment & 5059 & Gamma \\
\hline \multicolumn{3}{|l|}{ AEs } \\
\hline Major CV events & 318,482 & Gamma \\
\hline Major GI events & 31,198 & Gamma \\
\hline Healthcare resource use in non-opioid state & 3870 & Gamma \\
\hline \multicolumn{3}{|c|}{ Opioid treatment strategy (including non-opioids and opioids) } \\
\hline \multicolumn{3}{|l|}{ Drug treatment } \\
\hline Treatment (non-opioid treatments in non-opioid state) & 5059 & Gamma \\
\hline Treatment (monotherapy in opioid state) & 9826 & Gamma \\
\hline Treatment (combination therapy in opioid state) & 14,794 & Gamma \\
\hline \multicolumn{3}{|l|}{ AEs (non-opioid treatments) } \\
\hline Major CV events & 318,482 & Gamma \\
\hline Major GI events & 31,198 & Gamma \\
\hline \multicolumn{3}{|l|}{ AEs (opioid treatments) } \\
\hline Nausea/vomiting & 862 & Gamma \\
\hline Constipation & 911 & Gamma \\
\hline Somnolence & 0 & Gamma \\
\hline Fractures (tramadol) & 213,853 & Gamma \\
\hline \multicolumn{3}{|l|}{ Healthcare resource use (non-opioid state) } \\
\hline Non-opioid state & 3870 & Gamma \\
\hline With opioid treatments & 3517 & Gamma \\
\hline \multicolumn{3}{|l|}{ Surgery $^{\mathbf{b}}$} \\
\hline Cost intervention, knee & 518,429 & Gamma \\
\hline Cost intervention, hip & 522,129 & Gamma \\
\hline \multicolumn{3}{|l|}{ Post-surgery $^{b}$} \\
\hline Cost post-surgery, knee & 6424 & Gamma \\
\hline Cost post-surgery, hip & 5538 & Gamma \\
\hline
\end{tabular}

Medication costs were accounted for in the non-opioid and opioid health states and procedure costs were accounted for in the surgery and post-surgical health states. This is because there were no differences in the post-surgery treatment state dependent on pre-surgery treatment. Hence, the treatments in the post-surgery state for both strategies cancelled out in the model. All medication and procedure costs of the non-opioid, surgery and post-surgical health states were assumed to be the same in the non-opioid and opioid treatment strategies

AEs adverse events, $C V$ cardiovascular, GI gastrointestinal, NSAIDs nonsteroidal anti-inflammatory drugs

${ }^{a}$ Medical Data Vision Co. Ltd (MDV; Tokyo, Japan)

${ }^{\mathrm{b}}$ The same costs are applied here for both the opioid and non-opioid treatment strategies was cost effective comparing the non-opioid treatment strategy with the opioid treatment strategy for the surgeryeligible patients with knee OA at WTP of 5,000,000 JPY/ QALY (Fig. 4A). In addition, 52.12\% was observed at WTP for hip OA (Fig. 4B).

\subsection{Scenario Analyses}

\subsubsection{Scenario Using Lower Utility of Opioid Medications}

Table 6 shows the results for the scenario using the lower utility of opioid medications for the surgery-eligible patients with OA. In patients with knee OA, the opioid treatment 
Table 4 Utility values

\begin{tabular}{|c|c|c|c|c|c|}
\hline \multirow[t]{2}{*}{ Health state } & \multicolumn{2}{|l|}{ Knee } & \multicolumn{2}{|l|}{ Hip } & \multirow{2}{*}{$\begin{array}{l}\text { Type of } \\
\text { distribu- } \\
\text { tion }\end{array}$} \\
\hline & Base case & Scenario case & Base case & Scenario case & \\
\hline Non-opioids & 0.546 & Same as base case & 0.503 & Same as base case & Beta \\
\hline Only opioids & 0.538 & 0.333 & 0.498 & 0.435 & Beta \\
\hline Non-opioid/opioid combination & 0.539 & Same as base case & 0.516 & Same as base case & Beta \\
\hline Surgery & 0.480 & & 0.489 & & Beta \\
\hline Rehabilitation/physiotherapy & 0.559 & & 0.596 & & Beta \\
\hline Waiting for prosthesis & 0.400 & & 0.379 & & Beta \\
\hline Post-surgery (normal) & 0.683 & & 0.730 & & Beta \\
\hline Post-surgery (with complications) & 0.424 & & 0.556 & & Beta \\
\hline
\end{tabular}

Utility values were derived from García-Pérez et al. [33]

Table 5 Cost-effectiveness results of base-case analysis

\begin{tabular}{|c|c|c|c|c|}
\hline & \multicolumn{2}{|l|}{ Knee } & \multicolumn{2}{|l|}{ Hip } \\
\hline & Non-opioid & Opioid & Non-opioid & Opioid \\
\hline Total cost, JPY & 951,456 & $1,005,334$ & 902,739 & 956,868 \\
\hline $\begin{array}{r}\text { Incremental } \\
\text { costs, JPY }\end{array}$ & & 53,878 & & 54,129 \\
\hline QALY & 11.53 & 11.50 & 12.14 & 12.12 \\
\hline $\begin{array}{l}\text { Incremental } \\
\text { QALY }\end{array}$ & & -0.03 & & -0.02 \\
\hline $\begin{array}{l}\text { ICER, JPY per } \\
\text { QALY }\end{array}$ & & Dominated & & Dominated \\
\hline
\end{tabular}

ICER incremental cost-effectiveness ratio, JPY Japanese yen, $Q A L Y$ quality-adjusted life-years

strategy was dominated by the non-opioid treatment strategy with -0.27 incremental QALYs. Similarly, in patients with hip OA, the opioid treatment strategy was dominated by the non-opioid treatment strategy with -0.03 incremental QALYs.

\section{Discussion}

The base-case analysis found that the non-opioid treatment strategy had higher efficacy and was less expensive than the opioid treatment strategy in the surgery-eligible patients with OA of the knee and hip. Also, these results were related to the lower utility score in the opioid state and another high utility score in the post-surgical state. Hence, they should be considered together with the key assumptions, limitations and uncertainty inherent to the model.

The cost effectiveness of the opioid treatment strategy compared with the non-opioid treatment strategy may be attributable to earlier surgical intervention, resulting in higher utility in the post-surgical state than in all presurgical states, and having a considerable impact on the results. However, the contribution of earlier surgical intervention to cost effectiveness was not thoroughly revealed in this study. Hence, further research will be required.

Probabilistic sensitivity analysis demonstrated considerable uncertainty about the results of the base-case analysis and therefore it cannot be stated with certainty which treatment strategy has the best cost effectiveness. This is because no confidence intervals (or standard deviations) were available, as no clinical evidence could be used for the CEA (as treatment strategies are being compared rather than individual treatments). The standard deviation in the model was set equal to the mean as no confidence interval was available [46].

This cost-effectiveness model was based on the treatment practice for OA in Japan, taking into account treatments that are commonly employed for the management of OA of the hip and knee. Our analysis did not consider any additional costs associated with the illicit use of opioids because they are strictly controlled [10]. Our results are consistent with previous cost-effectiveness studies. Katz et al. found that tramadol-based strategies were dominated by one or more of the naproxen-based strategies [18]. Similar outcomes were reported in another study by Smith et al. [19], which concluded that the use of opioids was not cost effective in surgery-eligible patients with OA of the knee.

The main limitation of the study was that the transition probabilities of the health states were derived from the transition probabilities by severity according to the WOMAC scores based on the literature [27]. It was therefore assumed for the model that the transitions between the none/mild, moderate and severe pain states reflect the transitions between non-opioid, opioid and surgery health states, respectively. This approach was necessary because multiple treatments were included in each health state and no clinical studies were found that encompassed all relevant treatments. This methodology limits the conclusions that can be drawn from the results. Moreover, though a previous study reported 


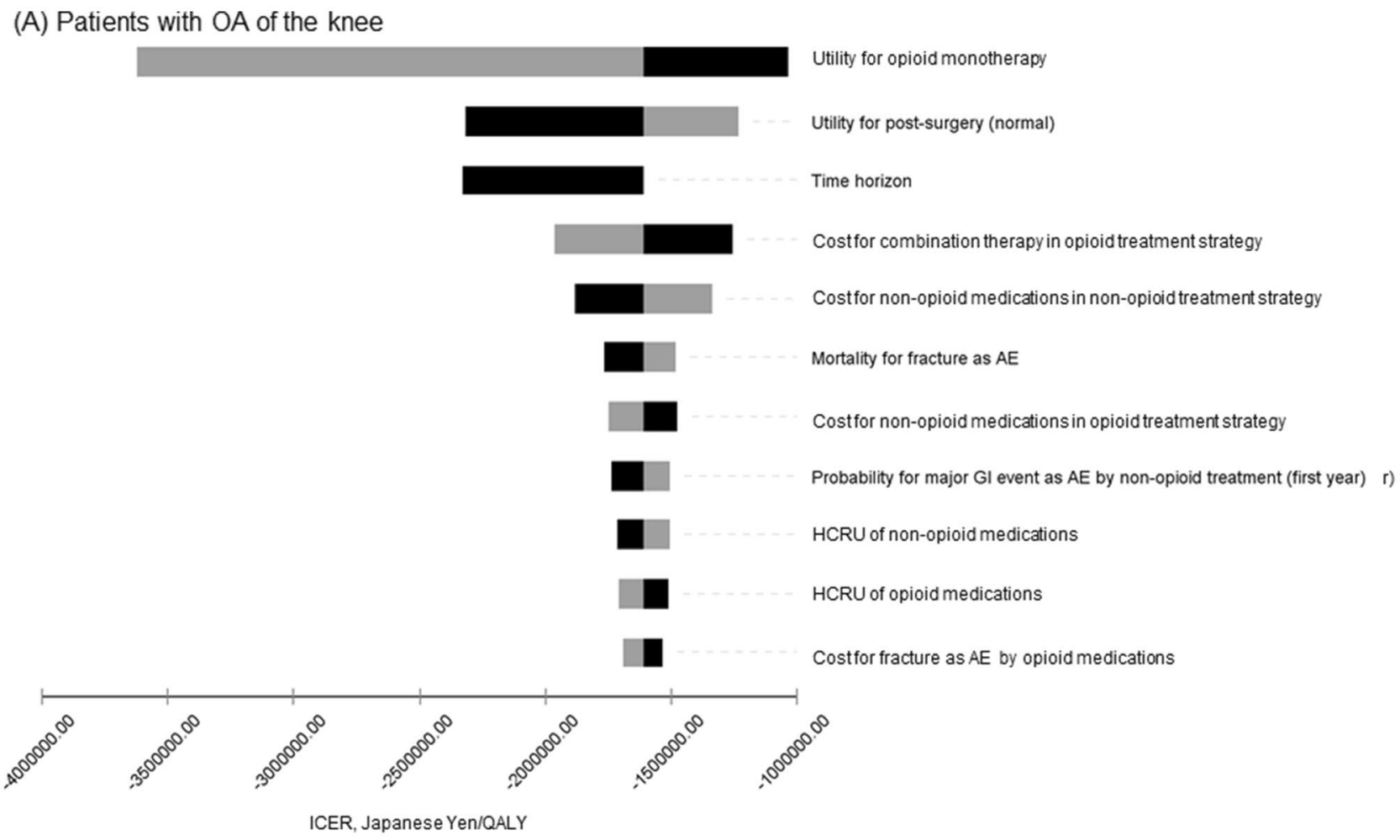

(B) Patients with OA of the hip

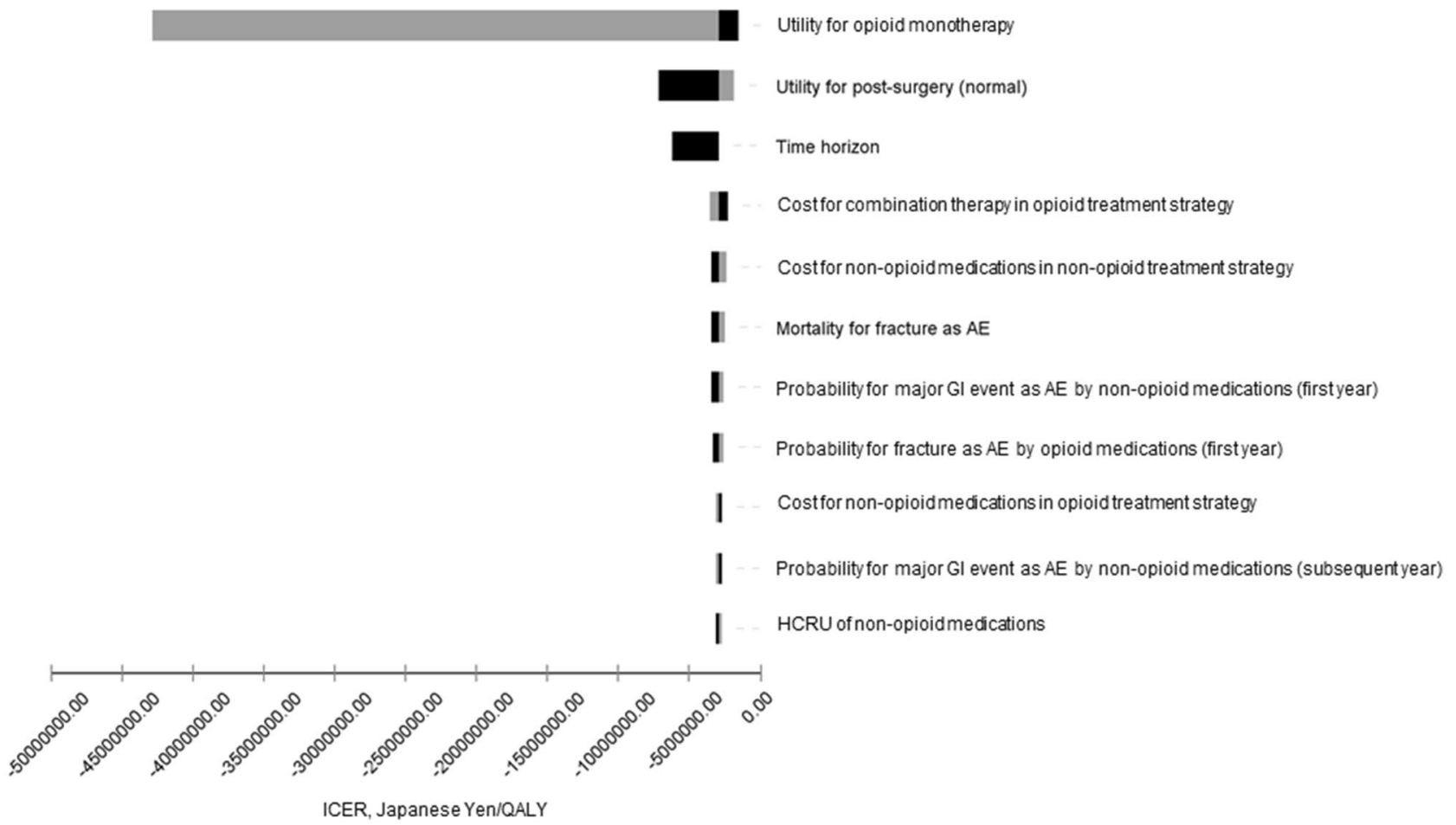

Fig. 2 Tornado diagrams, ICER, opioid treatment strategy versus non-opioid treatment strategy: A patients with OA of the knee; B patients with OA of the hip. Utilities were adjusted to a quarter value due to three-month cycles representing one cycle. Time horizon of variables was changed from 10 to 30 years (40-120 cycles). $A E$ adverse events, $C V$ cardiovascular, GI gastrointestinal, $H C R U$ healthcare resource use, ICER incremental cost-effectiveness ratio, $O A$ osteoarthritis 
(A) Patients with OA of the knee

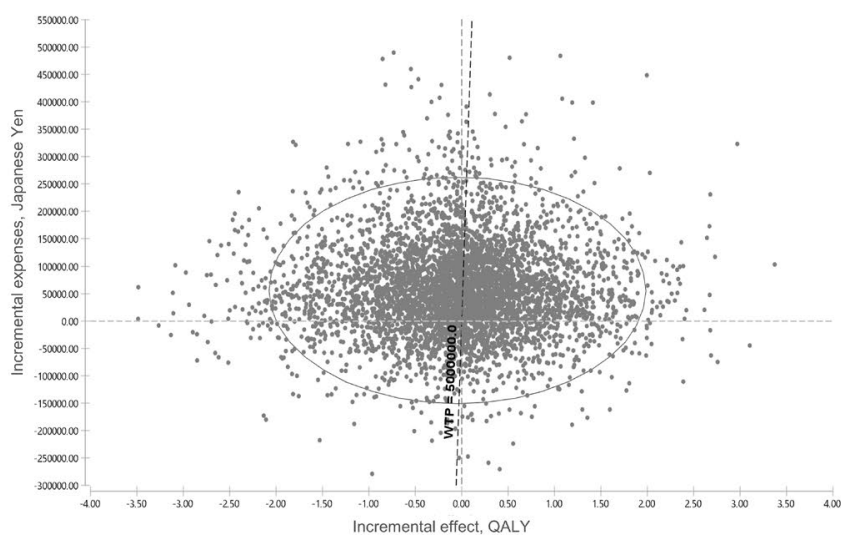

Fig. 3 Incremental cost-effectiveness plane for the base-case analysis, opioid treatment strategy versus non-opioid treatment strategy: A patients with OA of the knee; $\mathbf{B}$ patients with OA of the hip.
(B) Patients with $O A$ of the hip

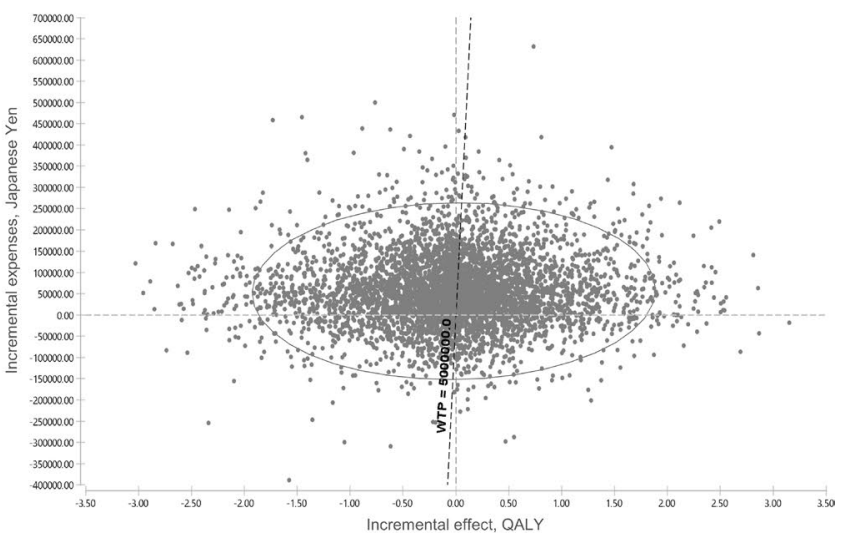

$\mathrm{WTP}=5$ million JPY/QALY. $J P Y$ Japanese yen, $O A$ osteoarthritis, $W T P$ willingness-to-pay, $Q A L Y$ quality-adjusted life-years
(A) Patients with OA of the knee

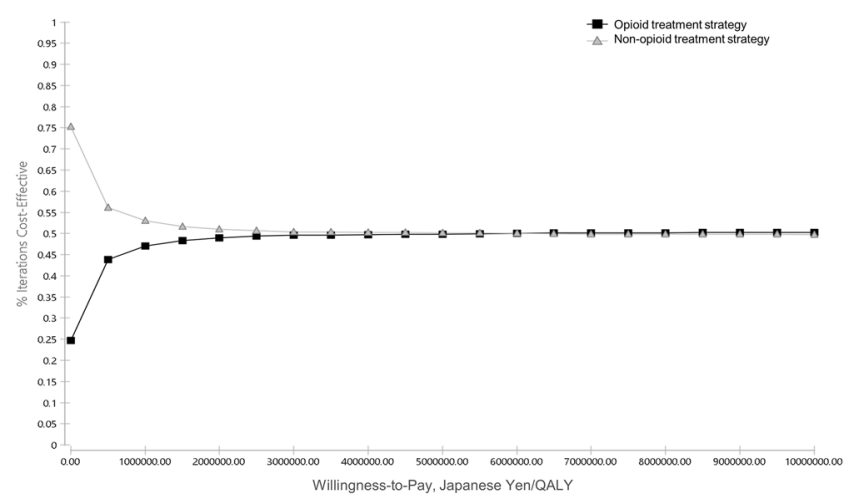

(B) Patients with OA of the hip

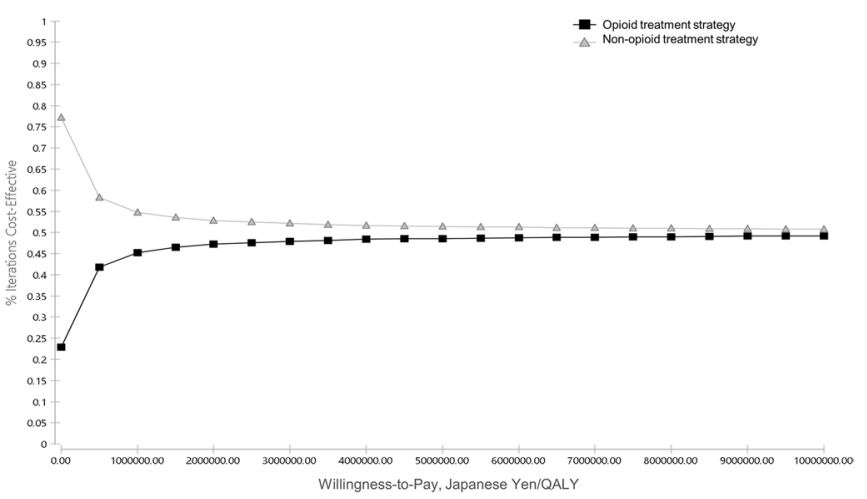

Fig. 4 Cost-effectiveness acceptability curves (CEACs) for A patients with OA of the knee; B patients with OA of the hip. OA osteoarthritis, $Q A L Y$ quality-adjusted life-years

Table 6 Cost-effectiveness results of the scenario using lower utility for opioids

\begin{tabular}{|c|c|c|c|c|}
\hline & \multicolumn{2}{|l|}{ Knee } & \multicolumn{2}{|l|}{ Hip } \\
\hline & Non-opioid & Opioid & Non-opioid & Opioid \\
\hline Total cost, JPY & 951,456 & $1,005,334$ & 902,739 & 956,868 \\
\hline $\begin{array}{r}\text { Incremental } \\
\text { costs, JPY }\end{array}$ & & 53,878 & & 54,129 \\
\hline QALY & 11.53 & 11.46 & 12.14 & 12.11 \\
\hline $\begin{array}{l}\text { Incremental } \\
\text { QALY }\end{array}$ & & -0.07 & & -0.03 \\
\hline $\begin{array}{l}\text { ICER, JPY per } \\
\text { QALY }\end{array}$ & & Dominated & & Dominated \\
\hline
\end{tabular}

ICER incremental cost-effectiveness ratio, $J P Y$ Japanese yen, $Q A L Y$ quality-adjusted life-years a difference in utility values for opioids and non-opioids [33], there is no difference in effectiveness for the opioid and non-opioid treatment strategies in this study, which suggests that cost-minimization analysis would be an interesting analysis to be conducted in the future.

Furthermore, no Japanese-specific data were found for the transition probabilities, incidence of AEs and utility values, and those used may therefore differ from the actual values in Japan.

Another limitation was that no AEs for surgery and post-surgical states were considered in the model as the utilities and costs of the AEs are an expected trade-off between both treatment strategies. 
The costs were calculated according to the MDV database, and cost items were estimated according to previous studies and guidelines [32, 34-36]. The ratio of patients, the daily dose and the frequency of doses were calculated by using the data set, and these were then multiplied by the unit price. One of the limitations of the MDV database is that it only includes patient data from large hospitals.

Finally, our model considered as the target population only patients who were eligible for surgery (TKA/THA), disregarding the fact that surgery depends on patients' preferences and that many elderly patients are not well enough to be able to undergo such procedures.

This study is an unconventional attempt to report a costeffectiveness analysis of the opioid treatment strategy versus the non-opioid treatment strategy in elderly and surgeryeligible patients with OA of the knee or hip in Japan. Despite these limitations, this health economic analysis evaluates the economic and clinical outcomes of the non-opioid treatment strategy versus the opioid treatment strategy in patients aged $\geq 65$ years with OA of the knee or hip in Japan who were eligible for TKA or THA according to the national clinical treatment pattern $[11,21]$.

\section{Conclusion}

This study suggests that a non-opioid treatment strategy is cost effective compared with an opioid treatment strategy in the management of surgery-eligible patients with OA of the knee or hip. However, as the underlying methodology is heavily based on assumptions, the outcome of the analysis cannot be considered as accurate, which in turn may affect the final conclusion of the non-opioid treatment strategy being cost effective. The results are consistent with the Japanese treatment guidelines and recommendations in previous studies.

Supplementary Information The online version contains supplementary material available at https://doi.org/10.1007/s41669-021-00292-5.

\section{Declarations}

Funding Pfizer Japan Inc. was the only direct sponsor of this study and fees were paid to IQVIA Solutions Japan K.K.

Conflict of interest Tomoyuki Takura received an advisory fee from Pfizer Japan Inc. Akira Yuasa, Naohiro Yonemoto, Nozomi Ebata and Koichi Fujii are full-time employees of Pfizer Japan Inc., and stockholders in Pfizer Inc. Sven Demiya and Hiroyuki Matsuda are full-time employees of IQVIA Solutions Japan K.K. Muneaki Ishijima has been on the speakers' bureau for Pfizer Japan Inc.

Data availability statement The data set used for the analysis was gathered from various public domains of the agencies (i.e., Ministry of
Health, Labour and Welfare of Japan, Bank of Japan, Organisation for Economic Co-operation and Development, and The World Bank) and hence is publicly available, but is also available from the corresponding author upon reasonable request. Standard statistical functions were used in $\mathrm{R}$ and no additional software code was developed.

Ethics approval Not applicable.

Consents Not applicable.

Author contributions All named authors meet the ICMJE criteria for authorship for this manuscript, take responsibility for the integrity of the work and have given final approval for this version of the manuscript to be published. All named authors contributed to the study design, model construction and reviewing of the manuscript.

Open Access This article is licensed under a Creative Commons Attribution-NonCommercial 4.0 International License, which permits any non-commercial use, sharing, adaptation, distribution and reproduction in any medium or format, as long as you give appropriate credit to the original author(s) and the source, provide a link to the Creative Commons licence, and indicate if changes were made. The images or other third party material in this article are included in the article's Creative Commons licence, unless indicated otherwise in a credit line to the material. If material is not included in the article's Creative Commons licence and your intended use is not permitted by statutory regulation or exceeds the permitted use, you will need to obtain permission directly from the copyright holder. To view a copy of this licence, visit http://creativecommons.org/licenses/by-nc/4.0/.

\section{References}

1. Bannuru RR, Schmid CH, Kent DM, Vaysbrot EE, Wong JB, McAlindon TE. Comparative effectiveness of pharmacologic interventions for knee osteoarthritis: a systematic review and network meta-analysis. Ann Intern Med. 2015;162(1):46-54.

2. Sadosky AB, DiBonaventura M, Cappelleri JC, Ebata N, Fujii K. The association between lower back pain and health status, work productivity, and health care resource use in Japan. J Pain Res. 2015;8:119.

3. Jordan K, Arden N, Doherty M, Bannwarth B, Bijlsma J, Dieppe P, et al. EULAR Recommendations 2003: an evidence based approach to the management of knee osteoarthritis: Report of a Task Force of the Standing Committee for International Clinical Studies Including Therapeutic Trials (ESCISIT). Ann Rheum Dis. 2003;62(12):1145-55.

4. Muraki S, Akune T, Oka H, En-Yo Y, Yoshida M, Saika A, et al. Association of radiographic and symptomatic knee osteoarthritis with health-related quality of life in a population-based cohort study in Japan: the ROAD study. Osteoarthr Cartil. 2010;18(9):1227-34.

5. Rice D, McNair P, Huysmans E, Letzen J, Finan P. Best evidence rehabilitation for chronic pain part 5: osteoarthritis. J Clin Med. 2019;8(11):1769. https://doi.org/10.3390/jcm8111769.

6. Brosseau L, Yonge KA, Robinson V, Marchand S, Judd M, Wells $\mathrm{G}$, et al. Thermotherapy for treatment of osteoarthritis. Cochrane Database Syst Rev. 2003;2003(4):CD004522. https://doi.org/10. 1002/14651858.CD004522.

7. Dawson J, Linsell L, Zondervan K, Rose P, Randall T, Carr A, et al. Epidemiology of hip and knee pain and its impact on overall health status in older adults. Rheumatology. 2004;43(4):497-504. 
8. Muraki S, Akune T, Oka H, Mabuchi A, En-Yo Y, Yoshida M, et al. Association of occupational activity with radiographic knee osteoarthritis and lumbar spondylosis in elderly patients of population-based cohorts: a large-scale population-based study. Arthritis Care Res Off J Am Coll Rheumatol. 2009;61(6):779-86.

9. Inoue K, Wicart P, Kawasaki T, Huang J, Ushiyama T, Hukuda S, et al. Prevalence of hip osteoarthritis and acetabular dysplasia in French and Japanese adults. Rheumatology. 2000;39(7):745-8.

10. Akazawa M, Mimura W, Togo K, Ebata N, Harada N, Murano H, et al. Patterns of drug treatment in patients with osteoarthritis and chronic low back pain in Japan: a retrospective database study. $\mathbf{J}$ Pain Res. 2019;12:1631.

11. Japanese Orthopaedic Association (JOA) Committee. OARSI recommendations for the management of hip and knee osteoarthritis, Part II: OASRI evidence-based, expert consensus guidelines adapted to Japanese by Japanese Orthopaedic Association (JOA) Committee on Clinical Practice Guideline on the Management of Osteoarthritis of the Knee 2012.

12. Kolasinski SL, Neogi T, Hochberg MC, Oatis C, Guyatt G, Block J, et al. 2019 American College of Rheumatology/arthritis foundation guideline for the management of osteoarthritis of the hand, hip, and knee. Arthritis Care Res (Hoboken). 2020;72(2):149-62. https://doi.org/10.1002/acr.24131.

13. Onishi E, Kobayashi T, Dexter E, Marino M, Maeno T, Deyo RA. Comparison of opioid prescribing patterns in the United States and Japan: primary care physicians' attitudes and perceptions. J Am Board Fam Med. 2017;30(2):248-54.

14. Kanai A. Issues of opioid analgesics and expectations of buprenorphine. Locomot Pain Front. 2017;6(2):52-9.

15. Hootman JM, Helmick CG, Barbour KE, Theis KA, Boring MA. Updated projected prevalence of self-reported doctor-diagnosed arthritis and arthritis-attributable activity limitation among US adults, 2015-2040. Arthritis Rheumatol. 2016;68(7):1582-7. https:// doi.org/10.1002/art.39692.

16. United States Bone and Joint Initiative. The burden of musculoskeletal diseases in the United States (BMUS) Forthcoming Rosemont, IL. https://www.boneandjointburden.org/fourth-edition/iiib10/osteo arthritis.

17. Itoh H, Saito T, Nojiri S, Hiratsuka Y, Yokoyama K. National burden of the pharmaceutical cost of wet compresses and its cost predictors: nationwide cross-sectional study in Japan. Heal Econ Rev. 2019;9(1):20. https://doi.org/10.1186/s13561-019-0238-6.

18. Katz JN, Smith SR, Collins JE, Solomon DH, Jordan JM, Hunter DJ, et al. Cost-effectiveness of nonsteroidal anti-inflammatory drugs and opioids in the treatment of knee osteoarthritis in older patients with multiple comorbidities. Osteoarthr Cartil. 2016;24(3):409-18.

19. Smith SR, Katz JN, Collins JE, Solomon DH, Jordan JM, Suter LG, et al. Cost-effectiveness of tramadol and oxycodone in the treatment of knee osteoarthritis. Arthritis Care Res (Hoboken). 2017;69(2):234-42. https://doi.org/10.1002/acr.22916.

20. Valdes A, Stocks J. Osteoarthritis and ageing. Eur Med J. 2018;3(1):116-23.

21. Zhang W, Moskowitz R, Nuki G, Abramson S, Altman RD, Arden $\mathrm{N}$, et al. OARSI recommendations for the management of hip and knee osteoarthritis, Part II: OARSI evidence-based, expert consensus guidelines. Osteoarthr Cartil. 2008;16(2):137-62.

22. Center for Outcomes Research and Economic Evaluation for Health, National Institute of Public Health $(\mathrm{C} 2 \mathrm{H})$. Guideline for preparing cost-effectiveness evaluation to the Central Social Insurance Medical Council. Version 2.0; approved 20 February 2019. https://c2h.niph. go.jp/tools/guideline/guideline_en.pdf. Accessed 15 July 2020.

23. Hasegawa M, Komoto S, Shiroiwa T, Fukuda T. Formal implementation of cost-effectiveness evaluations in japan: a unique health technology assessment system. Value Health. 2020;23(1):43-51. https://doi.org/10.1016/j.jval.2019.10.005.

24. THE WORLD BANK. Life expectancy at birth, total (years). 2020. https://data.worldbank.org/indicator/SP.DYN.LE00.IN. Accessed 15 July 2020.

25. Husereau D, Drummond M, Petrou S, Carswell C, Moher D, Greenberg D, et al. Consolidated Health Economic Evaluation Reporting Standards (CHEERS)-explanation and elaboration: a report of the ISPOR health economic evaluation publication guidelines good reporting practices task force. Value Health. 2013;16(2):231-50. https://doi.org/10.1016/j.jval.2013.02.002.

26. Nakamura M. Utilization of MDV data and data quality control. Jpn J Pharmacoepidemiol Yakuzai Ekigaku. 2016;21(1):23-5. https:// doi.org/10.3820/jjpe.21.23.

27. Zhang B, Lin H, Hunter DJ, Neogi T, Wise B, Choy E, et al. A multistate transition model for osteoarthritis pain change. Commun Stat Theory Methods. 2009;38(18):3297-306.

28. Piscitelli P, Iolascon G, Di Tanna G, Bizzi E, Chitano G, Argentiero A, et al. Socioeconomic burden of total joint arthroplasty for symptomatic hip and knee osteoarthritis in the Italian population: a 5 -year analysis based on hospitalization records. Arthritis Care Res (Hoboken). 2012;64(9):1320-7. https://doi.org/10.1002/acr.21706.

29. Ministry of Health, Labour and Welfare. Abridged life tables for Japan 2018. 2019. https://www.mhlw.go.jp/english/database/db-hw/ lifetb18/index.html. Accessed 15 July 2020.

30. Hara M, Hayashi K, Kitamura T, Honda M, Tamaki M. A nationwide randomized, double-blind, placebo-controlled physicians' trial of loxoprofen for the treatment of fatigue, headache, and nausea after hangovers. Alcohol. 2020;84:21-5. https://doi.org/10.1016/j.alcoh ol.2019.10.006.

31. Ushida T, Matsui D, Inoue T, Yokoyama M, Takatsuna H, Matsumoto $\mathrm{T}$, et al. Recent prescription status of oral analgesics in Japan in real-world clinical settings: retrospective study using a large-scale prescription database. Expert Opin Pharmacother. 2019;20(16):2041-52. https://doi.org/10.1080/14656566.2019. 1651840.

32. Japanese Society for Palliative Medicine. Clinical guidelines for cancer pain management. 2014.

33. García-Pérez L, Ramos-García V, Serrano-Aguilar P, Pais-Brito JL, de Mendoza MA, Martín-Fernández J, et al. EQ-5D-5 L utilities per health states in Spanish population with knee or hip osteoarthritis. Health Qual Life Outcomes. 2019;17(1):164.

34. Marra CA, Grubisic M, Cibere J, Grindrod KA, Woolcott JC, Gastonguay L, et al. Cost-utility analysis of a multidisciplinary strategy to manage osteoarthritis of the knee: economic evaluation of a cluster randomized controlled trial study. Arthritis Care Res. 2014;66(6):810-6.

35. Taguchi Y, Inoue Y, Kido T, Arai N. Treatment costs and cost drivers among osteoporotic fracture patients in Japan: a retrospective database analysis. Arch Osteoporos. 2018;13(1):45.

36. Kimura K, Kimura T, Ishihara M, Nakagawa Y, Nakao K, Miyauchi $\mathrm{K}$, et al. JCS 2018 guideline on diagnosis and treatment of acute coronary syndrome. Circ J. 2019;83(5):1085-196.

37. Powers WJ, Rabinstein AA, Ackerson T, Adeoye OM, Bambakidis $\mathrm{NC}$, Becker K, et al. 2018 guidelines for the early management of patients with acute ischemic stroke: a guideline for healthcare professionals from the American Heart Association/American Stroke Association. Stroke. 2018;49(3):e46-99.

38. Tsutsui $\mathrm{H}$, Isobe $\mathbf{M}$, Ito $\mathrm{H}$, Okumura $\mathrm{K}$, Ono $\mathbf{M}$, Kitakaze $\mathbf{M}$, et al. JCS 2017/JHFS 2017 guideline on diagnosis and treatment of acute and chronic heart failure-digest version-. Circ J. 2019;83(10):2084-184.

39. Hashiguchi M, Yamauchi N, Uchikura T, Mochizuki M. Cost comparative analysis of drug therapy for non-steroidal anti-inflammatory drug (NSAID)-induced gastric ulcer in Japan. Yakugaku Zasshi J Pharm Soc Jpn. 2008;128(4):585-94. 
40. Shiraishi Y, Kohsaka S, Sato N, Takano T, Kitai T, Yoshikawa T, et al. 9-Year trend in the management of acute heart failure in japan: a report from the national consortium of acute heart failure registries. J Am Heart Assoc. 2018;7(18):e008687. https://doi.org/10. 1161/jaha.118.008687.

41. Kinjo K, Sato H, Nakatani D, Mizuno H, Shimizu M, Hishida E, et al. Predictors of length of hospital stay after acute myocardial infarction in Japan. Circ J. 2004;68(9):809-15. https://doi.org/10. 1253/circj.68.809.

42. Yagi M, Yasunaga H, Matsui H, Morita K, Fushimi K, Fujimoto M, et al. Impact of rehabilitation on outcomes in patients with ischemic stroke: a nationwide retrospective cohort study in Japan. Stroke. 2017;48(3):740-6. https://doi.org/10.1161/strokeaha.116.015147.
43. Ministry of Health, Labour and Welfare. Various information of medical fee. 2020. https://shinryohoshu.mhlw.go.jp/shinryohoshu/ kaitei/. Accessed 15 July 2020.

44. Bank of Japan. Turnover of swap (US Dollar/Yen). 2020. https:// www.boj.or.jp/statistics/market/forex/fxdaily/index.htm/. Accessed 15 July 2020.

45. ORGANISATION FOR ECONOMIC CO-OPERATION AND DEVELOPMENT. Purchasing power parities (PPP) statistics purchasing power parities for GDP and related indicators. OECD. Stat. 2020. https://stats.oecd.org/Index.aspx?DataSetCode=CPL\#. Accessed 15 July 2020.

46. Briggs A, Claxton K, Sculpher M. Decision modelling for health economic evaluation. Oxford University Press, 2006. 